\title{
A Brief Analysis of the Causes and Countermeasures of Fog-Haze in Beijing-Tianjin-Hebei Region
}

\author{
Wenhan Zhang \\ Beijing National Day School, Beijing, China \\ Email: zhangwenh@163.com
}

How to cite this paper: Zhang, W. H. (2019). A Brief Analysis of the Causes and Countermeasures of Fog-Haze in Beijing-Tianjin-Hebei Region. Journal of Geoscience and Environment Protection, 7, 39-46. https://doi.org/10.4236/gep.2019.77004

Received: May 20, 2019

Accepted: July 21, 2019

Published: July 24, 2019

Copyright (อ 2019 by author(s) and Scientific Research Publishing Inc. This work is licensed under the Creative Commons Attribution International License (CC BY 4.0).

http://creativecommons.org/licenses/by/4.0/ c) (†) Open Access

\begin{abstract}
Since China broke the blockade and opened the country to the outside world, many township enterprises develop quickly. Together with the pollution caused by China's coal-burning as the main source of national energy, the pollution caused by small and medium-sized enterprises in towns and villages due to their small investment, low technology level and weak environmental awareness, and the pollution caused by a sharp increase in motor vehicle emissions lead to the fact that fog-haze has been rampant in China's cities and urban agglomerations for nearly two decades, especially in the Beijing-Tianjin-Hebei region. This paper sorted out the current situation of fog-haze and analyzed the causes of fog-haze from the two aspects of natural and man-made causes, discussed the harms of fog-haze to human body, environment and life, and put forward the concrete measures to solve the fog-haze problem.
\end{abstract}

\section{Keywords}

Beijing-Tianjin-Hebei Region, Fog-Haze, Causes, Harm

\section{Introduction}

Fog-haze is the mixture of fog and haze together. It is a blurred vision and cloudy phenomenon when the air moisture reaches a certain level. Both fog and haze are particulate matter floating in the atmosphere, which can worsen visibility and cause disastrous weather. But its composition and formation process are completely different. Fog is a natural weather phenomenon that usually forms when there is plenty of moisture, a breeze, and a stable atmosphere. It causes humidity to reach saturation, and water vapor in the air condenses into tiny 
droplets suspended in the air, resulting in reduced visibility near ground level. While haze is a collection of aerosols such as dust particles, smoke particles or salt particles discharged into the air, which is mainly caused by air pollution. The difference between haze and fog is that the relative humidity in haze is not large, while the relative humidity in fog is saturated. The core substance forming fog is water droplets, while the main substance forming haze is suspended particles in the air, also known as aerosol particles. At the same time, haze and light fog often appear at the same time, fog and haze can also be converted to each other under certain conditions. First, the formation of fog itself also requires some small particles as condensation nuclei. Secondly, fog often occurs in static weather conditions, at this time the pollutants in the air is not easy to spread, the duration of a long time can also cause air pollution. Generally speaking, some fog is mainly caused by saturated water vapor in the air, the concentration of pollutants is very low, this kind of poor visibility weather has a great impact on traffic, but there is no need to worry about its pollution problem. And some fog may also have a certain concentration of pollutants involved, at this time it will be accompanied by varying degrees of air pollution. In this case, as the temperature changes throughout the day, the relative humidity will increase or decrease correspondingly, and there is a phenomenon of mutual transformation between fog and haze. Fog and haze can be simply identified from the color, smell and humidity conditions. Fog is often milky white, with high humidity and no obvious smell. And haze humidity is small, often appears light gray, yellow, red and other colors, and may be accompanied by a slight pungent odor (Wu, 2015).

\section{The Causes of Fog-Haze in Beijing-Tianjin-Hebei Region}

Like other disasters, haze is the result of the combined action of natural and man-made factors, and has all the characteristics of a disaster system.

\subsection{The Natural Causes of Fog-Haze}

The western side and the northern side of the Beijing-Tianjin-Hebei region (see Figure 1) are the Taihang Mountains and the Yanshan Mountains, respectively. The terrain is relatively closed, which is not conducive to the diffusion of pollutants, but it's easy to form accumulation, and easy to form fog-haze (Li, 2016).

The formation and change of fog-haze pollution weather need certain meteorological conditions. The atmospheric static wind in the horizontal direction and the temperature inversion in the vertical direction are not conducive to the diffusion of atmospheric pollutants, which is the main reason for the formation of fog-haze pollution weather. Meteorologists call fog when water vapor suspended in the atmosphere condenses and visibility falls below 1000 meters. Fog itself is not pollution, but in the atmospheric environment producing fog, such as low temperature, weak air activity, low wind speed, stable atmosphere, etc., the pollution particles in the air are not easy to spread outward, which will cause the aggregation effect of pollutants near the ground. In the troposphere, temperature 


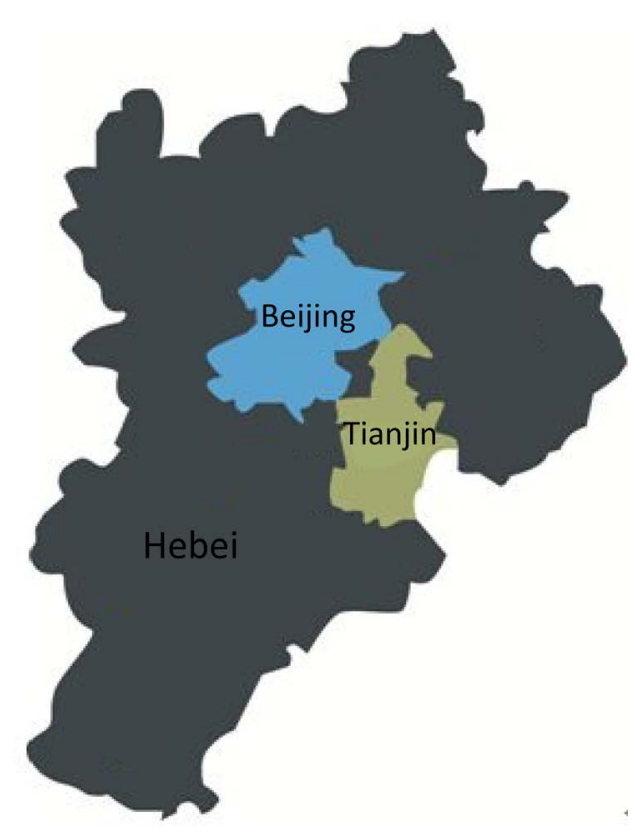

Figure 1. Map of Beijing-Tianjin-Hebei region.

normally decreases with height. Sometimes, however, there are anomalies in which the temperature increases with height. The appearance of temperature inversion is not conducive to the rising movement of the air, if there are pollutants, the pollutants will stay in place for a long time and cause pollution. Therefore, the adverse meteorological conditions characterized by low wind speed and temperature inversion are the external cause of fog-haze formation. Urban areas are frequently prone to haze weather, mainly due to the high building density in urban areas, which significantly slows down the wind speed in urban areas, resulting in the difficulty of aerosol particles diffusion in the air. Therefore, the fog-haze phenomenon is more serious in the Beijing-Tianjin-Hebei region with dense population and large number of enterprises. The cold air activity is weak, especially in autumn and winter. So it is easy to form the atmospheric inversion layer, which results in the blocked horizontal and vertical movement of the air, and the timely diffusion of pollutants, leading to the accumulation of pollutants in a certain range, and finally forming fog-haze (Ding, Li, \& Weng, 2010).

\subsection{The Man-Made Causes of Fog-Haze}

\subsubsection{The Industrial Structure and Energy Structure Are Unreasonable}

Since the reform and opening up, the economy of the Beijing-Tianjin-Hebei region has been developing rapidly, and various factories have developed quickly. But with the development of industry, the problem of environmental pollution also appears. In the Beijing-Tianjin-Hebei region, there are a large number of highly polluting and energy-consuming enterprises, such as steel mills, cement plants, oil refining and petrochemical plants, which not only emit waste gas, but also generate dust and ultra-fine particulate matter in the production process, which also aggravates the fog-haze. The energy consumption in the Beijing-Tianjin-Hebei region 
mainly relies on fossil energy such as coal and oil. And the major cause of haze is the excessive consumption of fossil energy such as coal and oil by the highly polluting and energy-consuming industries, which produces a large amount of sulfur dioxide, carbon dioxide, dust and fine particulate matter (Huang \& $\mathrm{He}$, 2013).

\subsubsection{Population Density Is High}

The population size of the Beijing-Tianjin-Hebei region reaches 110 million (according to the data of year 2013). The population density is 484 people per square kilometer, four times the national average. High population density has exceeded the bearing capacity of regional resources and environment, which is also an important economic factor causing serious fog-haze.

\subsubsection{Vehicle Exhaust Emissions Are Increasing Rapidly}

China has been the world's largest producer and seller of motor vehicles for eight consecutive years, according to data released by the ministry of environmental protection. The 2017 Annual Report on Prevention and Control of Motor Vehicle Pollution in China says vehicle exhaust pollution is an important source of air pollution in China. Large-scale automobile exhaust emissions should not be underestimated. The fog-haze in the Beijing-Tianjin-Hebei region is largely caused by vehicle emissions, and the contribution of vehicle exhaust to PM2.5 cannot be ignored.

\section{The harms of Fog-Haze}

The Beijing-Tianjin-Hebei region has rapid economic development and high population density, so the consequences of haze disasters are more serious, which are mainly reflected in human body, environment and life. Please see Table 1 (Wen \& Zhu, 2014).

\subsection{The Harm of Fog-Haze to Human Body}

First, the composition of haze is very complex, including hundreds of atmospheric chemical particles. For patients with chronic respiratory diseases such as bronchial asthma, chronic bronchitis, obstructive emphysema and chronic obstructive pulmonary disease, haze weather can make the condition acute attack or acute aggravation. Long-term exposure to these conditions can also lead to lung cancer. Secondly, the effect of the fog-haze days on the human cardiovascular

Table 1. The impact of fog-haze in Beijing-Tianjin-Hebei region.

\begin{tabular}{c}
\hline \multicolumn{1}{c}{ Aspects } \\
\hline $\begin{array}{c}\text { Human body } \\
\text { Lung cancer cases in Beijing increased by } 60 \% \text { in } 2014 \text { compared with 2004; The } \\
\text { death rate of lung cancer in Hebei province in } 2012 \text { is 306\% higher than in the 1970s }\end{array}$ \\
Environment Acid rain frequency and acidity increased \\
Life $\quad \begin{array}{l}\text { In January } 2013 \text { alone, heavy fog-haze in Beijing caused about } 300 \text { million yuan in } \\
\text { direct and indirect losses to the transportation industry }\end{array}$ \\
\hline
\end{tabular}


and cerebrovascular disease is also very serious. It can hinder normal blood circulation, cause cardiovascular disease, hypertension, coronary heart disease, cerebral hemorrhage, may induce angina pectoris, myocardial infarction, heart failure and so on. It can also make chronic bronchitis appear pulmonary heart disease. In addition, the fog-haze is not conducive to the growth of children. Due to the decrease of sunshine in foggy days and insufficient ultraviolet radiation in children, vitamin D production in the body is insufficient, and the absorption of calcium is greatly reduced. Severe cases can cause babies to rickets and children to grow slower. What's more, continuous foggy days have both psychological and physical effects on people. From the psychological point of view, fog days will give people a dull, depressed feeling, will stimulate or aggravate psychological depression.

\subsection{The Impact of Fog-Haze on the Environment}

Fog-haze contains all kinds of chemical components and toxic substances, such as acid, alkali, salt, ammonia and other chemical content than normal atmospheric level. Moreover, fog-haze hinders sunlight and is not conducive to plant photosynthesis. It not only interferes with the normal growth of plants, but also harms animals and adversely affects the ecological environment. It is also prone to acid rain, which causes pollution of rivers, corrosion of buildings and acidification of land, and is harmful to human health, ecosystem and building facilities (Cao \& Yan, 2015).

\subsection{The Harm of Fog-Haze to Life}

When there is fog-haze weather, due to poor air quality, poor visibility, it is easy to cause traffic congestion and traffic accidents. In daily driving or walking, people should observe the road more, so as to avoid danger. In the fog-haze weather, a large number of fine particles fall on crops to inhibit their respiration. At the same time, the haze weather leads to insufficient photosynthesis of crops, resulting in reduced crop yield and harvest, and affecting animal husbandry and agricultural production. Due to the fog-haze weather, many people who usually exercise outdoors are forced to give up their exercise, and schools may be closed when there is heavy smog, which has a serious impact on people's normal life (Rokjin, Jacoba, Kumar, \& Yantoscaa, 2006).

\section{Measures to Control Fog-Haze in the Beijing-Tianjin-Hebei Region}

\subsection{Strengthen Research on the Particularity of Fog-Haze in the Beijing-Tianjin-Hebei Region}

According to a large number of field observation data in the Beijing-Tianjin-Hebei region, due to the continuous expansion of urban area and the shortening of urban space, the self-purification function of nature is constantly weakened. Chemical pollutants are transported between cities through air flow, resulting in over- 
lapping of different types of high concentration pollutants and chemical coupling. A large number of secondary pollutants are produced, which is quite different from the single pollution in other areas. In January 2014, the chemical composition of strong haze pollutants in the Beijing-Tianjin-Hebei region was a mixture of the haze in London in 1952 and that in Los Angeles in the United States in the middle of the 20th century. Moreover, the characteristic sand aerosols produced by desertification in northern China, degradation of grassland in Inner Mongolia, and land degradation in farming-pastoral areas in Hebei province are superimposed. Therefore, the research results of biological effects obtained in Europe and America based on local measurement cannot be analogized to the biological effects in the Beijing-Tianjin-Hebei region. To solve the haze problem in this region, local scientists need to do field research (Guo \& Liu, 2014).

\subsection{Adjust Industrial Structure and Optimize Layout of Area Economy}

The Beijing-Tianjin-Hebei region should strictly comply with the planning requirements of main functional areas and clearly define the industrial development direction in line with their respective functional positioning, energy conservation and environmental protection requirements. Beijing will focus on the disablement of industries that do not meet the capital's functional positioning, and give full play to the advantages of modern service industry, information industry and cultural and creative industry. Tianjin should focus on high-end manufacturing, developing high-end manufacturing industries such as automobile, equipment manufacturing, aerospace, new energy and new materials according to its own advantages. Hebei province should focus on cutting overcapacity at a higher level to reduce overcapacity in high-polluting industries such as steel, coal and building materials, resolutely shut down enterprises with backward environmental protection facilities, strictly approve new projects for environmental protection, improve product processes, and achieve industrial transformation and upgrading. Hebei province should give priority to the development of producer services, vigorously develop living services, and give full play to the advantages of area round Beijing-Tianjin region. In addition, it is necessary to strengthen the coordination of the three industries at the national level and adopt policies to promote the construction of ecological industrial parks across administrative regions. Collaborative innovation among the three regions should be encouraged and science and technology should be used to promote industrial upgrading. At the same time, China's monsoon climate dominated the country, most of the country's summer prevailing northwest wind, and winter prevailing southwest wind. A change in the wind direction will change the direction of diffusion of the polluting gas. Therefore, the government should adjust the industrial layout reasonably according to the local climate conditions. The more polluting factories should be moved downwind of the prevailing wind direction of the city or to the place with the minimum wind frequency, which can effectively reduce the industrial production process of urban air pollution. 


\subsection{Optimize Urban Planning and Spatial Pattern}

Urban planning should be formulated and strictly implemented in a scientific way and the issue of population-environment-resources should be properly handled. Resources and environmental conditions, population size and green space should be incorporated into the overall urban planning. Urban land should be planned scientifically, urban green land and the area covered by vegetation should be increased, and the rate of urban greening should be improved. The government should make scientific plans for the layout of various industrial parks, new urban towns and new districts, and build urban "wind tunnels" so that the layout of urban space is conducive to the diffusion of air pollutants.

\subsection{Reduce Pollution Sources}

The coordination of motor vehicle emission management in the three regions should be strengthened, emission standards should be improved, and the sharing of motor vehicle emission supervision data and unified punishment measures across regions should be realized. The number of motor vehicles in cities should be controlled and the elimination of yellow label automobiles should be accelerated. The fuel quality of motor vehicles should be improved and the production and consumption of new energy vehicles should be encouraged by policies. Change regional logistics mode of transport, vigorously develop railway transport, promote multimodal transport, and reduce the dependence on road freight. In addition, public transportation should vigorously be developed, urban traffic management should be coordinated and urban road congestion should be reduced. Fully implement the permit system for pollution discharge, strengthen supervision and inspection of major pollutants in heavily polluting industries to meet discharge standards, and make it mandatory for enterprises to install desulphurization, denitrification, dust removal and other environmental protection facilities in their major pollutant discharge sources.

\section{Conclusion}

The generation of fog-haze is the result of the interaction of many factors, such as nature, society and human activities, and its governance will be a long-term and complex process. Therefore, an in-depth analysis of fog-haze disaster from a systematic perspective is of great significance for fog-haze governance. Fog-haze in the Beijing-Tianjin-Hebei region has become a major topic of work and life in the region. But because of the particularity and complexity of haze in this region, when adjusting the energy consumption rate and reducing the coal consumption, a suitable and sustainable idea could be adopted. A lot of very microscopic analysis and work need to be done in order not to destroy the economic livelihood source of the people in the area (US Environmental Protection Agency, 2003).

\section{Conflicts of Interest}

The authors declare no conflicts of interest regarding the publication of this paper. 


\section{References}

Cao, H. Y., \& Yan, Z. C. (2015). Effects of Fog-Haze on Crops. Biological Bulletin, 50, 10-12.

Ding, Y., Li, J. H., \& Weng, P. F. (2010). Transport and Transformation Characteristics of Aerosol Particles in Dense Fog Weather. Journal of Shanghai University, 16, 226-231.

Guo, J. H., \& Liu, Y. W. (2014). China's Urban Haze Weather Governance Industrial Structure Adjustment. Journal of Northwest University, 44, 85-89.

Huang, Y. M., \& He, L. Y. (2013). Urbanization, Environmental Pollution and Residents' Subjective Well-Being-Empirical Evidence from China. China Soft Science, 12, 82-93.

Li, X. Y. (2016). Empirical Analysis of Haze Influencing Factors in Beijing-Tianjin-Hebei Region. Ecological Economy, 32, 144-150.

Rokjin, J., Jacoba, D., Kumar, N., \& Yantoscaa, R. (2006). Regional Visibility Statistics in the United States: Natural and Transboundary Pollution Influences, and Implications for the Regional Haze Rule. Atmospheric Environment, 40, 5405-5423.

https://doi.org/10.1016/j.atmosenv.2006.04.059

US Environmental Protection Agency (2003). Guidance for Estimating Natural Visibility Conditions under the Regional Haze Program. EPA-444/B-03-005.

Wen, K., \& Zhu, E. J. (2014). Development Report of Beijing-Tianjin-Hebei Region-Measurement of Bearing Capacity and Countermeasures (pp. 12-13). Beijing: Social Sciences Academic Press.

Wu, Z. G. (2015). Integrated Study on Haze Control in Beijing-Tianjin-Hebei (p. 3). Beijing: Beijing Science Press. 